Thomas Spencer, Roberta Pierfederici, Oliver Sartor, Nicolas Berghmans, Sascha Samadi, Manfred Fischedick, Katharina Knoop, Steve Pye, Patrick Criqui, Sandrine Mathy, Pantelis Capros, Panagiotis Fragkos, Maciej Bukowski, Aleksander Śniegocki, Maria Rosa Virdis, Maria Gaeta, Karine Pollier, Cyril Cassisa

\title{
Tracking sectoral progress in the deep decarbonisation of energy systems in Europe
}

Originally published in:

Energy Policy, 110 (2017), 509-517

DOI: 10.1016/j.enpol.2017.o8.o53 
Thomas Spencer $a$,

Roebrta Pierfederici a

Oliver Sartor a

Nicolas Berghmans a

Sascha Samadi b

Manfred Fischedick $b$

Katharina Knoop b

Steve Pye c

Patrick Criqui d

Sandrine Mathy d

Pantelis Capros $e$

Panagiotis Fragkos $e$

Maciej Bukowskif

Aleksander Sniegockif

Maria Rosa Virdis $g$

Maria Gaeta $g$

Karine Pollier $h$

Cyril Cassisa h

\section{Tracking sectoral progress in the deep decarbonisation of energy systems in Europe}

a The Institute for Sustainable Development and International Relations, Paris, France

b Wuppertal Institute for Climate, Environment and Energy, Wuppertal, Germany

c University College London Energy Institute, London, United Kingdom

d Grenoble Applied Economics Lab, Saint Martin d'Hères, France

e Energy Economy Environment Modelling Laboratory, Athens, Greece

f WiseEuropa, Warsaw, Poland

g ENEA, Rome, Italy

h Enerdata, Grenoble, France

* Corresponding author:

Thomas Spencer

The Institute for Sustainable Development and International Relations (IDDRI)

41, rue du Four

75006 Paris

France

E-mail: thomas.spencer@iddri.org 
This is the author's version of a work that was accepted for publication. Changes resulting from the publishing process, such as editing, corrections and structural formatting, may not be reflected in this document. Changes may have been made to this work since it was submitted for publication. A definitive version was subsequently published in the Journal cited above. 
Acknowledgements: This article has received financial support from the French government in the framework of the programme "Investissements d'avenir", managed by ANR (the French National Research Agency) under the reference ANR-10-LABX-01.

Abstract: Decarbonisation of energy systems requires deep structural change. The purpose of this research was to analyse the rates of change taking place in the energy systems of the European Union (EU), in the light of the EU's climate change mitigation objectives. Trends on indicators such as energy intensity and carbon intensity of energy were compared with decadal benchmarks derived from deep decarbonisation scenarios for the electricity, residential, transport, and industry sectors. The methodology applied provides a useful and informative approach to tracking decarbonisation of energy systems. The results show that the EU has made significant progress in decarbonising its energy systems. On a number of indicators assessed the results show that a significant acceleration from historical levels is required in order to reach the rates of change seen on the future benchmarks for deep decarbonisation. The methodology applied provides an example of how the research community and international organisations could complement the transparency mechanism developed by the Paris Agreement on climate change, to improve understanding of progress toward low-carbon energy systems.

Keywords: energy system decarbonisation; EU climate policy; policy monitoring 


\section{Introduction}

The European Union (EU) has introduced ambitious objectives to decarbonise its economy, namely a reduction of GHG emissions by 80-95\% by 2050 (European Council, 2009) and a mid-term target of an at least $-40 \%$ reduction of GHG emissions by 2030 , both compared to 1990 levels. This latter target has been submitted as the EU's joint "nationally-determined contribution" under the Paris Agreement (European Union, 2015). Numerous studies show that reaching such deep long-term emissions reductions requires profound structural change to energy systems (Bataille et al., 2016a; European Commission, 2011a, 2011b; IEA and IRENA, 2017; Spencer et al., 2015).

There has been increasing efforts to ensure an adequate tracking of progress towards long-term decarbonisation. Such tracking efforts are complicated by the inertia of the energy system; the multiple and interdependent pathways and options for decarbonisation; and the range of drivers, endogenous and exogenous to policy, of decarbonisation. In order to address this challenge, the European Commission has proposed a system of indicators and Member State reporting to track progress towards the EU's 2030 decarbonisation goals (European Commission, 2015).

This paper contributes to this debate in a number of ways. It reviews the available literature tracking the EU's progress towards deep decarbonisation by 2050 (section 2). It develops a methodology to track energy system decarbonisation in the EU (section 3). It applies this methodology to the EU, for the power, residential, industry and transport sectors (section 4). Finally, overarching policy and research implications of the findings are discussed in the conclusion (section 5).

\section{Literature Review}

There is a growing literature exploring roadmaps to decarbonisation in the EU. At the EU level, perhaps the most well-known among these is the European Commission's "Roadmap to a competitive lowcarbon economy in 2050" (European Commission, 2011a), and the Energy Roadmap (European Commission, 2011b). At the EU level, the Commission has recently published "The Clean Energy For All 
Europeans" package (European Commission, 2016b) which includes fully updated model-based energy scenarios involving deep emission reductions and legislative action to foster energy transition to 2030 .

Capros et al. (2014) provide a detailed comparison of large-scale energy system models used in the analysis of EU decarbonisation pathways, while a companion paper studies multiple scenarios across these models for the deep decarbonisation of the energy system by 2050 (Capros et al., 2014b). This paper finds that deep decarbonisation scenarios across different models display some key commonalities, and that in the short-term the failure to deploy the necessary enabling conditions for longer-term transformation can jeopodize the feasibility of long-term energy system decarbonisation (Capros et al., 2014b, pp. 244). This supports the argument developed in section 3 below that studying short-term energy system change can provide insights into progress towards long-term decarbonisation objectives.

At the national level, recent work has also focused on developing long-term low-carbon pathway scenarios. For instance, the Deep Decarbonisation Pathways Project presented a number of $2^{\circ} \mathrm{C}$ compatible pathways to 2050 for France, Germany, Italy and the UK (Bataille et al., 2016a). Several EU member state governments have also recently developed national climate or energy plans extending out to 2050, including the UK (HMG, 2011), France (MEDDEM, 2015), Germany (BMUB, 2016), Italy (MiSE, 2013), Denmark (Kebmin, 2011), Finland (TEM, 2014), the Netherlands (Ministry of EL\&I, 2011; Ministry of lenM, 2011), Sweden (Naturvardsverket, 2012), and Portugal (Portuguese Environment Agency, 2012). Knopf et al. (2013) and Foerster et al. (2013) analysed long-term decarbonisation scenarios for a number of EU counties (France, Germany, Italy, Sweden, and UK), and find that while different supply-side technology mixes are deployed, outcomes on indicators such as carbon intensity of energy consumption and energy intensity were similar.

At the industry and individual sector level, long term decarbonisation trajectories or roadmaps have been explored by several authors, both in academic literature and in the grey literature; for instance, 
in the chemicals sector (Cefic, 2013), the steel sector (Neuhoff et al., 2014a), the cement sector (Neuhoff et al., 2014b), and the power sector (European Climate Foundation, 2013).

To date, however, the potential uses of long term decarbonisation pathways for real-time policy evaluation has only just begun to be explored, both in the literature or in national policy frameworks. A significant contribution in this regard is (Bataille et al., 2016b). This paper focuses on a number of uses of decarbonisation pathways, including as a tool for structuring national policy formulation, building stakeholder consensus, and for revealing enabling conditions to make pathways a reality. Another important contribution comes from (Mathy et al., 2016). The latter article explores ways in which long term decarbonisation trajectories can be used to manage uncertainty and risk in the policy making process, and focuses in particular on the role of "dynamic" indicators.

At the national governmental level, the UK has institutionalised the use of long-term decarbonisation scenarios as a means of evaluating current climate policy (for example (Committee on Climate Change, 2016)). The European Commission publishes every three or so years an assessment of current policy trajectories in the form of the so-called EU Reference Scenario (European Commission, 2016a). Meanwhile, the European Environment Agency's annual "Trends and Projections" report (European Environment Agency, 2015) is an invaluable guide to EU and national progress in reducing emissions. However, it is nevertheless largely a descriptive rather than evaluative document, as its evaluation of progress is not explicitly linked to any normative long-term pathway for individual sectors. To the extent that it is evaluative, policy evaluation tends to focuses on 10 to 15 year emissions trends based on requirements under the EU's Monitoring Mechanism Regulation and Effort Sharing Decision (European Parliament and Council, 2013).

Thus, while progress is being made, there is still an important gap - both in the academic literature and in policy circles - when it comes to the use of normative long-term decarbonisation scenarios for the purposes of both ex ante and "real time" policy evaluation. This paper is a therefore intended as a contribution toward filling this gap. 


\section{Methodology}

The methodology described in the following paragraphs does not allow for a deductive conclusion to be reached regarding whether the EU and its Member States are on track for deep decarbonisation. In any case, the pathways towards the 2050 objective are too varied, uncertain and complex to allow such a clear-cut judgement. The methodology allows for the gathering of a large quantity of structured data on the decarbonisation of the EU energy system and the comparison of these observed changes with long-term decarbonisation scenarios. On this basis, expert judgement can draw an inductive conclusion regarding the likely adequacy of current sectoral decarbonisation trends, in the light of the EU's long-term objective of an 80\% reduction in GHGs by 2050.

The methodology rests on the understanding that the inertia of socio-economic systems, in particular the energy system, places significant mid-term constraints upon transformation pathways towards ambitious long-term mitigation objectives (Clarke et al., 2014, ff. 462). The achievement of long-term mitigation actions thus depends on short and mid-term actions to unlock "...the potential for deep GHG-emissions reductions several decades from now" (Clarke et al., 2014, pp. 464), through for example energy technology innovation and deployment, avoidance of infrastructure lock-in, or the control of energy demand growth. The extensive literature summarized by the IPCC shows that the study of long-term scenarios can generate insights into the nature, timing, magnitude and uncertainties of the mid-term energy system changes required for plausible long-term transformation pathways (Bruckner et al., 2014). In turn, the analysis of recent historical data against these mid-term indicators can be used to derive insights into the adequacy of current energy system change in the light of long-term objectives, particularly if the historical data analysed includes leading indicators such as investments and technology deployment. For example, the International Energy Agency (IEA) also uses an approach of model-derived mid-term benchmarks on indicators selected according to, inter alia, the Kaya identity, against which current changes in energy systems and technology deployment are compared (IEA, 2017, 2016). Certainly, the approach taken in this paper has limitations, including 
the uncertainties and diversity inherent in long-term pathways and the potential for structural breaks in energy system pathways; limitations in data availability to track, for example, leading indicators such as investments in energy efficiency; and the complexity of causal relationships between ultimate and proximate drivers of emissions outcomes (Blanco et al., 2014). Care should be taken in interpreting short-term indicators in terms of progress towards long-term objectives, and a broader contextual knowledge of decarbonisation pathways and policies must be applied in interpreting results.

The starting point for the methodology of this study is the sectoral Kaya identity. The Kaya identity allows the identification of the drivers of aggregate emissions changes, and the isolation and analysis of those most targeted by policy (generally speaking, sectoral energy and carbon intensity). In this study, the analysis focused largely on energy and carbon intensity of four sectors, i.e. electricity, transport, residential buildings and industry.

13 EU28 level and Member State level deep decarbonisation scenarios were gathered. Scenarios covered the EU28 in aggregate, and the UK, France, Germany, Poland, and Italy individually. These scenarios were developed in the context of different recent projects, but had a number of common features. Firstly, all represent very ambitious mitigation scenarios, reaching emissions levels compatible with the objective of limiting warming to $2^{\circ} \mathrm{C}$, i.e. a reduction of at least $80 \%$ against 1990 levels by 2050 in GHGs for developed countries (Metz et al., 2007, chapter 13.3.3). Secondly, all scenarios were developed using a comprehensive, technologically explicit, and well-validated energy system model. Thirdly, all scenarios were reported in a comparable, structured and detailed reporting template, allowing the choice of benchmarks from comparable parameters across the variables of the sectoral Kaya identity (for example, energy intensity of passenger transport).

These scenarios were analysed in order to derive sectoral benchmark ranges, representing for each decade to 2050 the changes required to reach deep decarbonisation across each parameter. Ranges were chosen rather than single values in order to reflect diversity of possible decarbonisation strategies as well as the diversity of circumstances of the EU Member States. These scenarios have 
been published in the following studies (Bukowski, 2013; Criqui et al., 2015; Hillebrandt et al., 2015; Paroussos et al., 2016; Pye et al., 2015; Virdis et al., 2015).

Finally, an extensive database was gathered for the historical performance of the EU28 and all of its Member States on each of the sectoral Kaya identity parameters. It should be noted that while the database of historical performance contains each EU Member State, for reasons of concision the following sections and figures present results only for the EU28, UK, France, Germany, Poland, and Italy, as well as the 'best' and 'worst' performing Member States on each indicator. The main databases used to build this database were (Enerdata, 2017, 2016). This performance data was analysed in the light of the sectoral benchmark ranges identified from the deep decarbonisation scenarios. This allowed the comparison of observed trends with the requirements of deep decarbonisation by 2050 . It also allowed the identification of upcoming challenges for policy and provides a framework for considering the adequacy of proposed policies.

\section{Results}

\subsection{Electricity Sector Results}

\subsubsection{Defining the Future Benchmark}

In the scenario literature assessed, in the upcoming decades 2020-2030 and 2030-2040 the compounded annual average rate of improvement of carbon intensity of electricity production reaches $-5.6 \%$ per year and $-10.3 \%$ per year respectively (the median value of scenarios assessed). Expressed in absolute terms this equates to a reduction in carbon intensity of $-13.6 \mathrm{gCO}_{2} / \mathrm{kWh}$ per year in the decade 2020-2030 and -14.4 $\mathrm{gCO}_{2} / \mathrm{kWh}$ per year in the decade 2030-2040 (median value of the scenarios assessed).

\subsubsection{Current Trends}

Figure 1 shows the main results of the comparison of the historical improvement in the carbon intensity of electricity production with the change in this indicator seen in the deep decarbonisation 
scenarios studied in this analysis and presented in section 4.1.1. It shows the compounded annual average change in the carbon intensity of electricity historically; and then in each decade to 2050 in the scenarios assessed. It can be seen that between 2000 and 2010 the carbon intensity of electricity declined by $-1.7 \%$ per year for the EU28, accelerating to $-2.15 \%$ per year in the period 2010 to 2014 . Over the period between 2000 and 2014 this amounted an improvement in absolute terms of about $5.8 \mathrm{gCO}_{2} / \mathrm{kWh}$ per year for the EU28 in aggregate, or a rate of $1.85 \%$ per year. The results imply that a significant acceleration in the rate of carbon intensity improvement of electricity production is required in the decade $2020-2030$ to be in line with the benchmark for deep decarbonisation.

Figure 1: historical improvement of carbon intensity of electricity supply compared to future benchmarks from deep decarbonisation scenarios $(\% \text { change } y-0-y)^{1}$

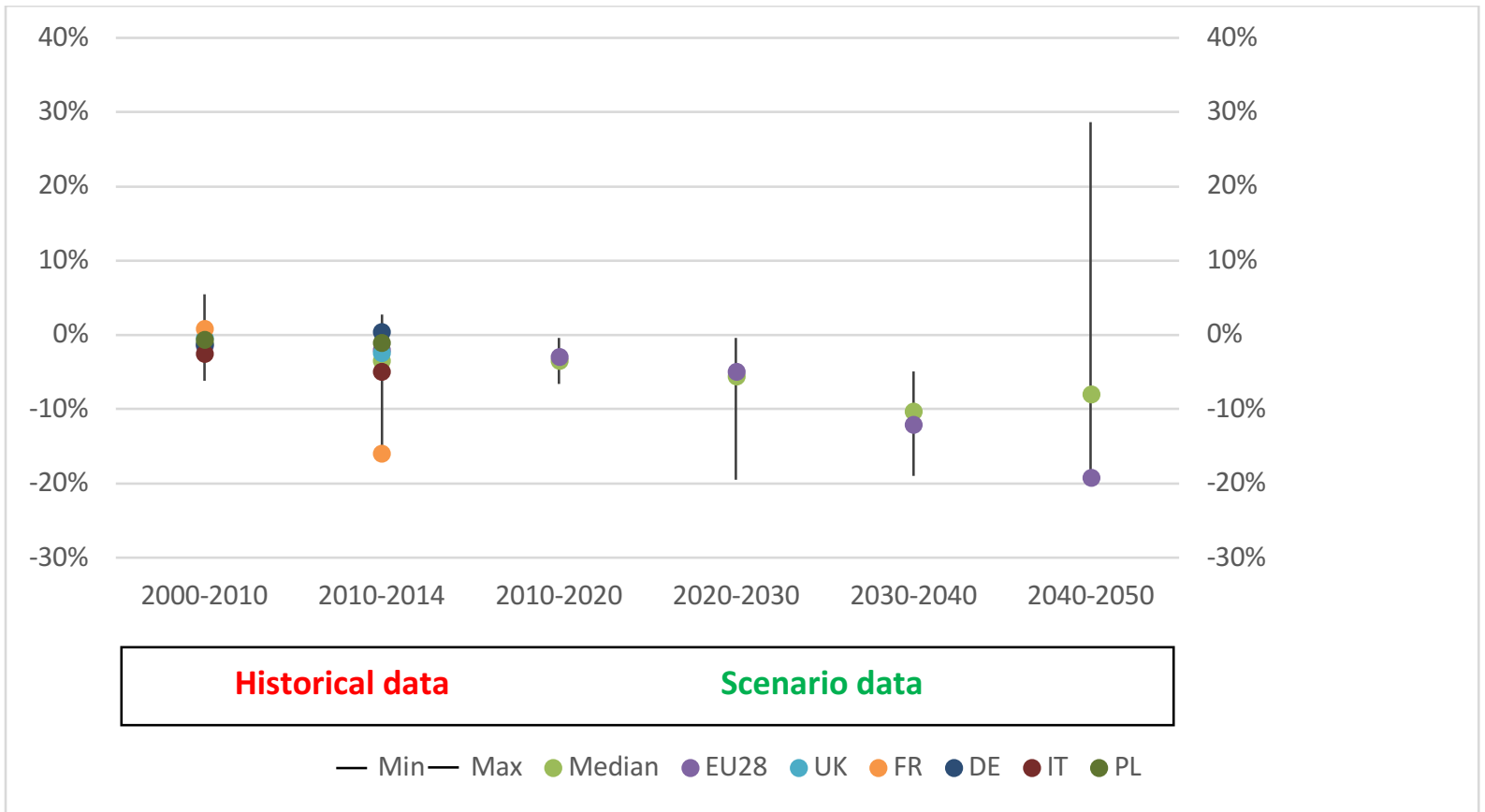

Source: authors based on data from (Bukowski, 2013; Criqui et al., 2015; Enerdata, 2016b;

Hillebrandt et al., 2015; Paroussos et al., 2016; Pye et al., 2015; Virdis et al., 2015).N.B. for historical data, median, min and max refer to those values among all EU28 Member States. For future scenario

\footnotetext{
${ }^{1}$ N.B. the large maximum value for 2040-2050 is due to one outlier scenario for France, which increases the carbon intensity of electricity (from a very low base) in this decade due to a switch towards gas for balancing intermittent renewables. The absolute carbon intensity in this scenario remains very low.
} 
data, median, min and max refer to these values from the scenario dataset compiled for UK, France, Germany, Italy, Poland, and the EU28.

\subsection{Residential Building Sector Results}

\subsubsection{Defining the Future Benchmarks}

In the scenario data assessed, the energy intensity of the residential sector declines by $-1.8 \%$ per year in the decade 2020-2030 and -2.0\% per year in the decade 2030-2040 (median value of the scenarios assessed). Energy intensity is defined as residential final energy consumption (FEC) per $\mathrm{m}^{2}$ of floorspace $\left(\mathrm{kWh} / \mathrm{m}^{2}\right)$. In absolute terms, this decline equates to a reduction of about $-2.8 \mathrm{kWh} / \mathrm{m}^{2}$ per year in the decade 2020 to 2030, and $-1.3 \mathrm{kWh} / \mathrm{m}^{2}$ per year in the decade 2030 to 2040 .

The paper also analyses the carbon intensity of residential FEC, defined as direct and indirect $\mathrm{CO}_{2}$ emissions per unit energy of residential FEC. In the scenario data assessed, this indicator declines by 2.9\% per year in the decade $2020-2030$ and $-3.4 \%$ per year in the decade $2030-2040$ (median of all scenarios assessed). This equates to a reduction of $-3.3 \mathrm{gCO}_{2} / \mathrm{kWh}$ per year in the decade 2020 to 2030 and $-2.9 \mathrm{gCO}_{2} / \mathrm{kWh}$ in the decade 2030 to 2040 (median of all scenarios assessed). The drivers of this change are on the one hand the accelerated decarbonisation of electricity supply, and on the other hand the shift towards low-carbon energy carriers, notably electricity.

\subsubsection{Current Trends}

Figure 2 shows the annual improvement of energy intensity of the residential buildings sector. Between 2000 and 2010 the EU28 in aggregate improved the energy intensity of the residential buildings sector of at a rate of $-2.0 \%$ per year, and $-1.3 \%$ per year in the period 2010 to 2013 . This equates to an improvement in absolute terms of $-5 \mathrm{kWh} / \mathrm{m}^{2}$ per year over the period 2000 to 2013. The Member States showing the strongest improvement were Romania, the United Kingdom, and Latvia, which reduced this indicator by $-11.6,-7.4$, and $-6 \mathrm{kWh} / \mathrm{m}^{2}$ per year respectively in the period 2000 to 2013. As shown in figure 3 below, there is also a large spread in the historical performance of EU Member States, evident in the spread of min and max values in the historical data. Over the period 2000 to 2013, Italy, Finland, Latvia, and Spain were the worst performing Member States on this 
indicator, which changed by $+0.6,-0.7,-0.8,-1.4 \mathrm{kWh} / \mathrm{m}^{2}$ per year respectively. The results imply that progress on this indicator is broadly in line with the benchmarks derived from the scenario data, at least at the EU28 level. For the EU28, the corresponding rate of decline for the whole period 20002013 was $-1.8 \%$ per year.

Figure 2: historical improvement of energy intensity in the residential building sector compared to future benchmarks from deep decarbonisation scenarios (\% change y-o-y)

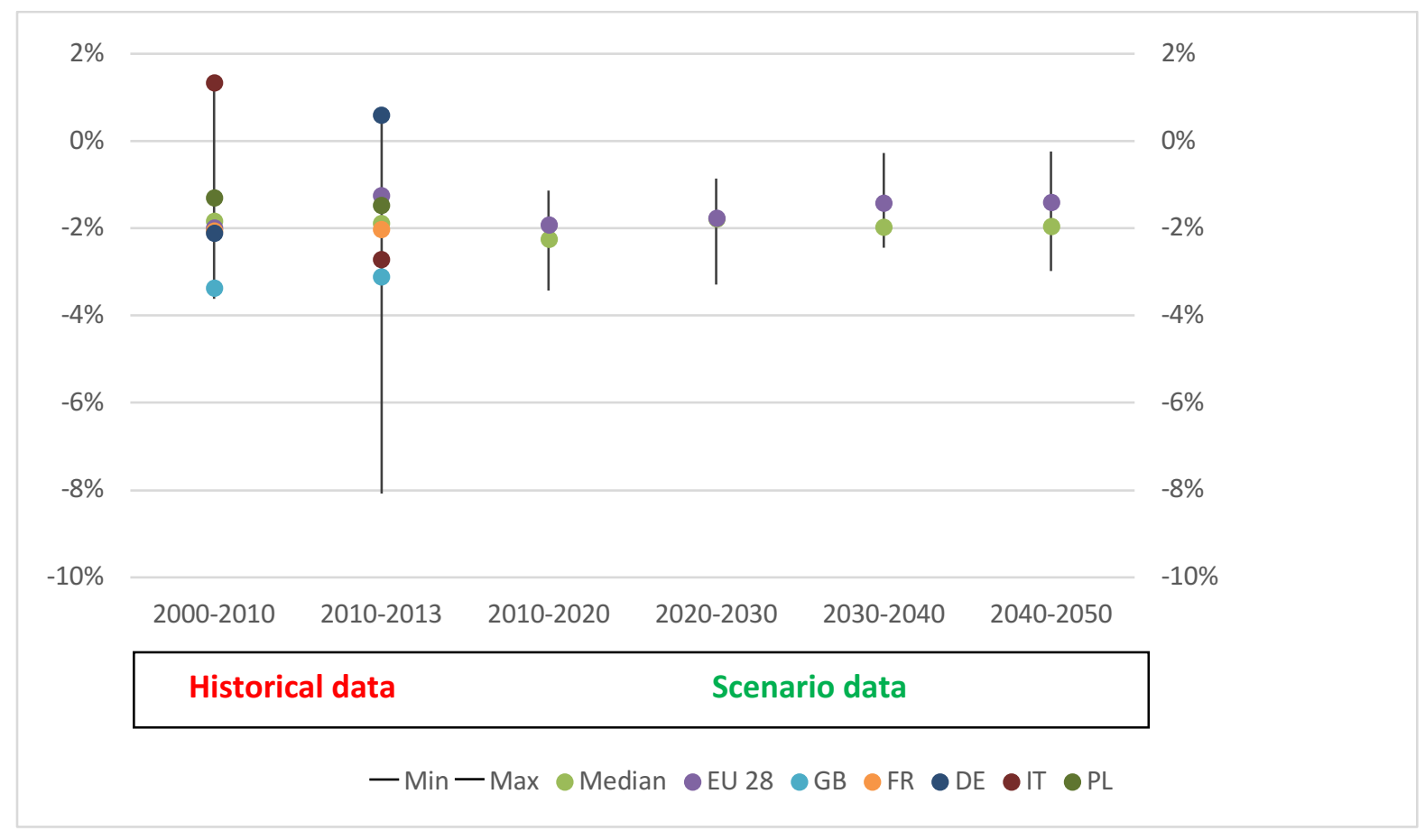

Source: authors based on (Bukowski, 2013; Criqui et al., 2015; Enerdata, 2016a; Hillebrandt et al., 2015; Paroussos et al., 2016; Pye et al., 2015; Virdis et al., 2015). N.B. for historical data, median, min and max refer to those values among all EU28 Member States. For future scenario data, median, min and max refer to these values from the scenario dataset compiled for UK, France, Germany, Italy, Poland, and the EU28.

Figure 3 shows the results for the indicator of carbon intensity of residential building sector FEC. Between 2000 and 2012, the EU28 reduced the carbon intensity of residential energy consumption by 
$-0.6 \%$ per year, equating to an improvement of $-1.64 \mathrm{gCO}_{2} / \mathrm{kWh}$ per year. In percentage terms, the top performing Member States were Sweden, Denmark, Finland, Belgium and Lithuania, which improved this indicator by $-53 \%,-47 \%,-31 \%,-23 \%,-21 \%$ between 2000 and 2012 respectively. The performance of Sweden is particularly notable, reaching an absolute level $31.1 \mathrm{gCO}_{2} / \mathrm{kWh}$. The worst performing Member States were Romania, Bulgaria, Luxembourg, Estonia, and the United Kingdom, which saw changes on this indicator of $+28 \%,+16 \%,+12 \%,+7 \%$, and $+1 \%$ respectively across the period. The results imply that a significant acceleration of the decline in carbon intensity of residential FEC is required in the coming decade $2020-2030$ in order to be in line with the future benchmark for deep decarbonisation.

Figure 3: historical improvement of carbon intensity of energy in the building sector compared to future benchmarks from deep decarbonisation scenarios $(\% \text { change } y-0-y)^{2}$

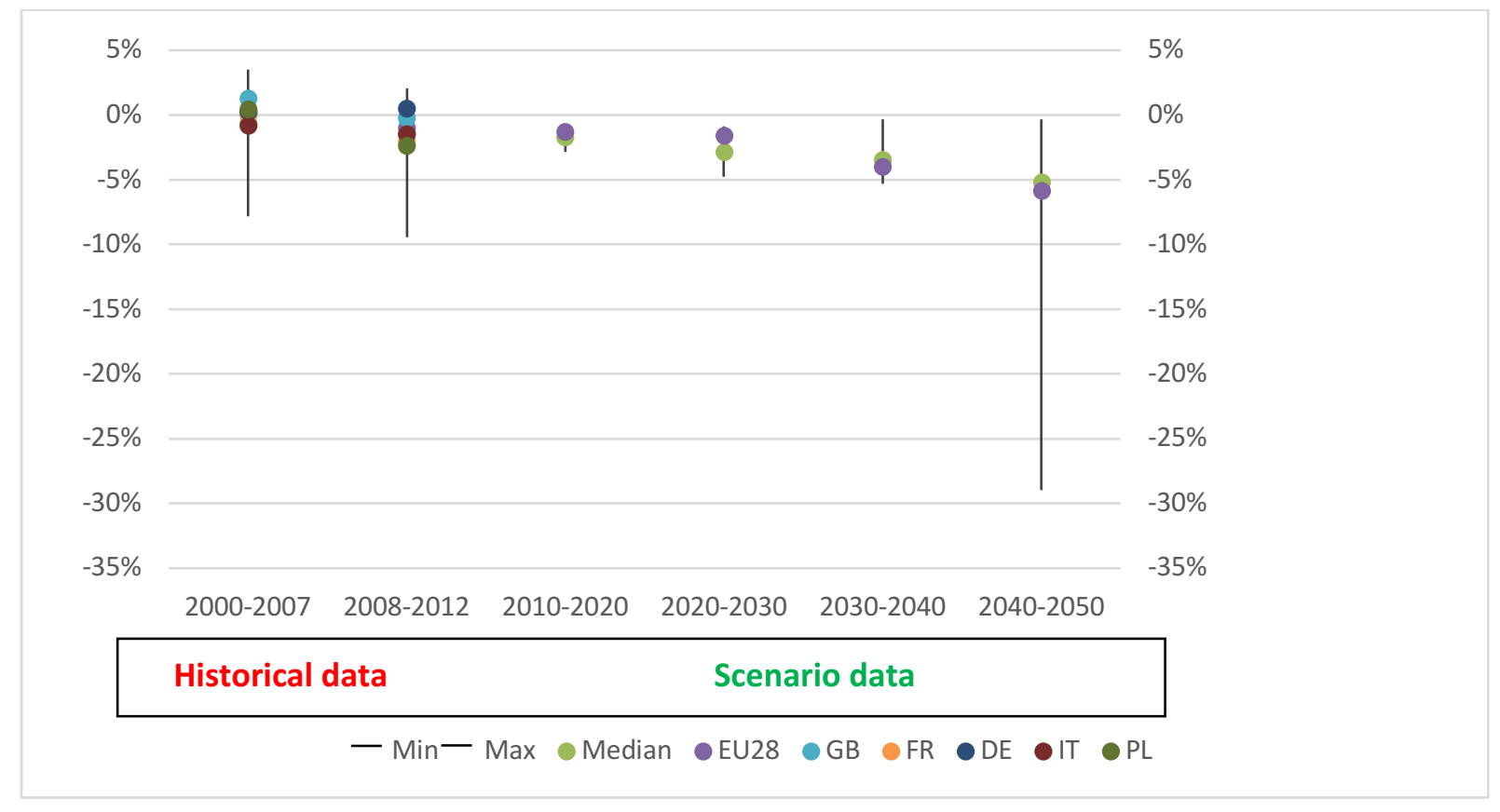

Source: authors based on (Bukowski, 2013; Criqui et al., 2015; Enerdata, 2016a; Hillebrandt et al., 2015; Paroussos et al., 2016; Pye et al., 2015; Virdis et al., 2015). N.B. for historical data, median, min and max refer to those values among all EU28 Member States. For future scenario data, median, min

\footnotetext{
2 The min value in the decade 2040-2050 is dragged down by two outlier scenarios for Italy which reach extremely low levels of $\mathrm{CO} 2$ intensity of buildings final energy consumption, as low as 1.96 gCO2/kWh
} 
and max refer to these values from the scenario dataset compiled for UK, France, Germany, Italy, Poland, and the EU28.

\subsection{Transport Sector Results}

\subsubsection{Defining the Future Benchmarks}

In the scenario data assessed, the energy intensity of passenger transport (all modes, defined at passenger transport FEC per passenger kilometre) declines at a rate of $-2.4 \%$ per year and $-2.3 \%$ per year in the decades 2020-2030 and 2030-2040 respectively (median of all scenarios assessed). This equates to a median scenario value of $0.255 \mathrm{kWh} / \mathrm{pkm}$ in 2030 and $0.189 \mathrm{kWh} / \mathrm{pkm}$ in 2040 . This compares to a "best in class" value of $0.3128 \mathrm{kWh} / \mathrm{pkm} 2012$ for Latvia in 2012, and an EU28 value of $0.4 \mathrm{kWh} / \mathrm{pkm}$ in 2012. In the scenarios assessed in this study, the energy intensity of freight transport, defined as freight FEC per tonne kilometre $(\mathrm{kWh} / \mathrm{t}-\mathrm{km})$, declines by $-1.2 \%$ and $-1.3 \%$ per year respectively in the decades 2020-2030 and 2030-2040 (median of all scenarios assessed).

The scenarios assessed in this study did not break down transport $\mathrm{CO}_{2}$ emissions into freight and passenger sub-sectors. For this reason, the analysis in this paper is of the carbon intensity of transport FEC as a whole, defined as direct and indirect transport $\mathrm{CO}_{2}$ emissions/transport FEC. In the decades 2020-2030 and 2030-2040 the carbon intensity of transport energy declines at a rate of -1.1\% per year and $-2.2 \%$ per year respectively (median of the scenarios assessed). Interestingly, on this indicator the scenarios developed at Member State level (for Poland, the United Kingdom, France, Germany and Italy) display some divergences with the EU28 scenarios analysed in this paper. In the national scenarios, the deployment of alternative fuel vehicles is stronger already in the decade 2020 to 2030 and this drives down the carbon intensity of transport energy at a faster rate in this decade (see the median of all scenarios assessed versus the EU28 value in Figure 6 below).

\subsubsection{Current Trends}

Figure 4 presents the indicator of energy intensity of passenger transport. For the EU28 in aggregate this indicator improved by $-6.3 \%$ in total across the period between 2000 and 2012, with a notable 
trend break around the 2007/8 economic crisis (see figure). Over the whole period 2000 to 2012, this represents an improvement of $-0.54 \%$ per year. The five best performing Member States on this indicator were Greece, Sweden, the United Kingdom, Germany and France, which reduced the energy intensity of passenger transport by $-35.3 \%,-15.0 \%,-14.0 \%,-12.1 \%$ and $-11.4 \%$ respectively in total across the period. The five worst performing Member States were the Netherlands, Poland, Cyprus, Spain and the Czech Republic, which increased the energy intensity of passenger transport by $+6.6 \%$, $+14.6 \%,+16.9 \%,+18.7 \%$, and $+33.0 \%$ respectively in total. Assessing the drivers of these Member State differences is beyond the scope of this paper, but with many poorer Member States among the belowaverage performers on this indicator, it is possible that a major driver for energy intensity increases in some countries has been a shift from public to private transport modes. The results imply that a significant acceleration of energy intensity improvements in passenger transport are required to be in line with the future benchmark for deep decarbonisation. 


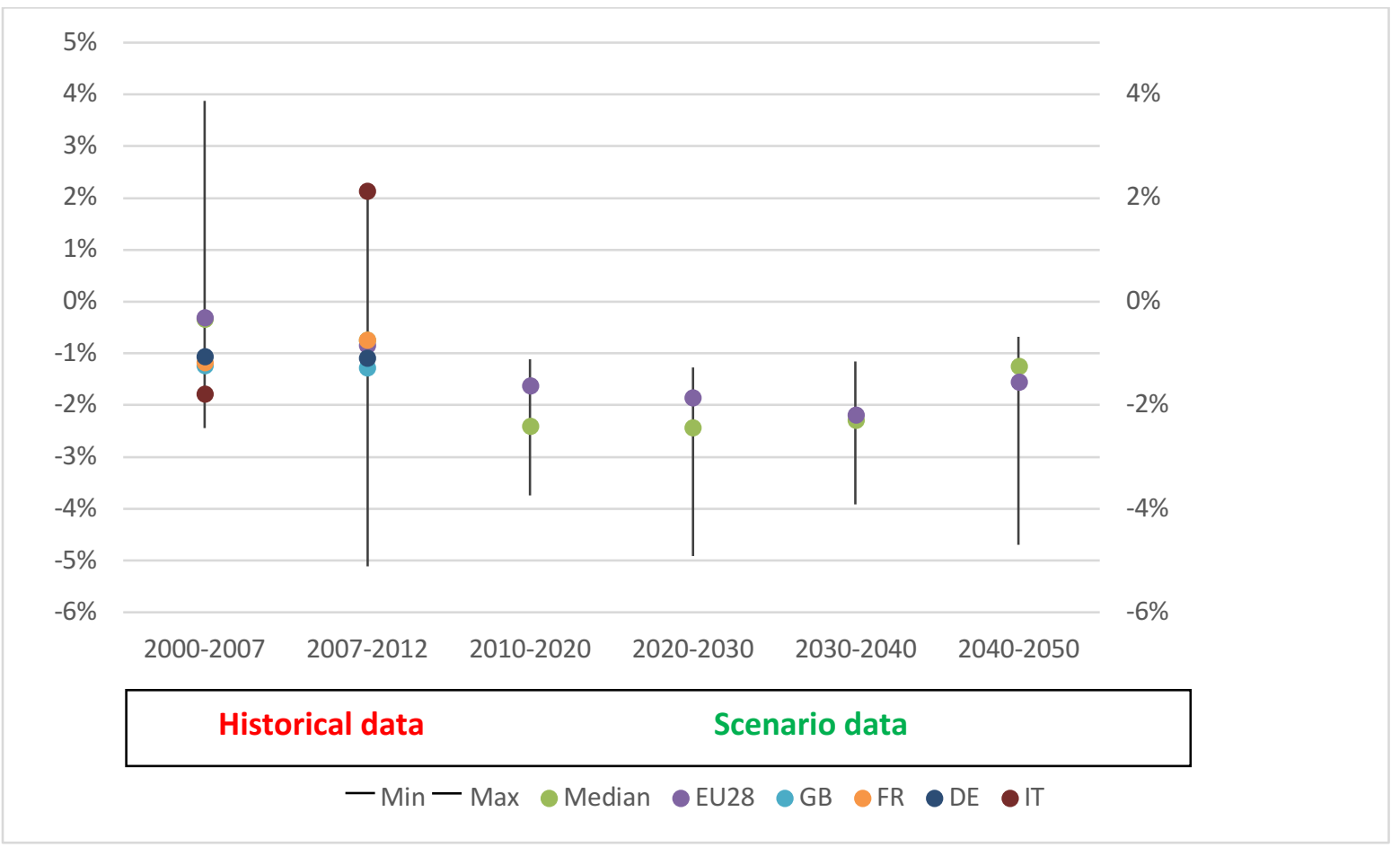

Source: authors based on (Criqui et al., 2015; Enerdata, 2016a; Hillebrandt et al., 2015; Paroussos et al., 2016; Pye et al., 2015; Virdis et al., 2015). N.B. for historical data, median, min and max refer to those values among all EU28 Member States. For future scenario data, median, min and max refer to these values from the scenario dataset compiled for UK, France, Germany, Italy, and the EU28.

Figure 5 presents the results for the energy intensity of freight transport. Between 2000 and 2013, the EU28 reduced the energy intensity of freight transport by $-8.2 \%$ in total, which equates to a rate of 0.7\% per year. The top performing Member States on this indicator were Latvia, Slovenia, Germany, Poland and Austria, which reduced the energy intensity of freight transport by $-36 \%,-31.4 \%,-21.7 \%$, $18.1 \%$, and $-16.9 \%$ respectively in total. The Member States which increased this indicator the most were Sweden, Finland, Greece, Italy and Ireland, which increased the energy intensity of freight

\footnotetext{
${ }^{3}$ Data on energy consumption for passenger transport are only available to 2012 for all EU Member States, and hence this date is used.
} 
transport by $+16.7 \%,+42.2 \%,+45.6 \%,+49.4 \%$, and $+53.2 \%$ respectively. The presence here of several crisis-hit periphery Member States suggests the importance of the cyclical effects of the crisis leading to organisational inefficiencies in the freight transport system. The results suggest that a moderate acceleration of the rate of decline of freight transport energy intensity is required to be in line with the future benchmark for deep decarbonisation.

Figure 5: historical improvement of energy intensity of freight transport compared to future benchmarks from deep decarbonisation scenarios (\% change y-o-y)

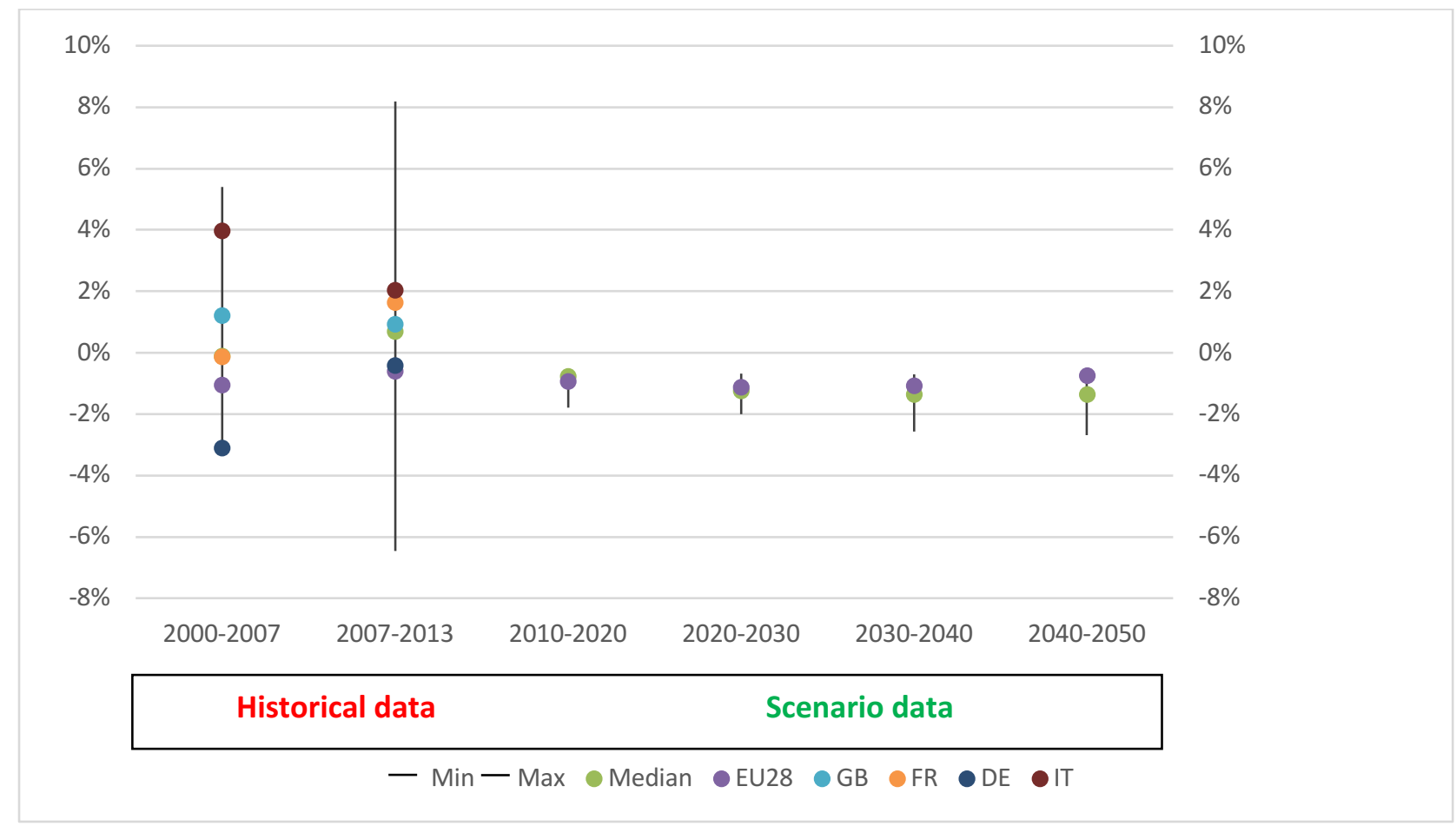

Source: authors based on (Criqui et al., 2015; Enerdata, 2016a; Hillebrandt et al., 2015; Paroussos et al., 2016; Pye et al., 2015; Virdis et al., 2015). N.B. for historical data, median, min and max refer to those values among all EU28 Member States. For future scenario data, median, min and max refer to these values from the scenario dataset compiled for UK, France, Germany, Italy, and the EU28.

Figure 6 below presents the carbon intensity of transport energy for the transport sector as a whole. For the EU28 this indicator has fallen by $-3.6 \%$ in the period 2000 to 2012 in total, a rate of $-0.31 \%$ per 
year. The best performing Member States on this indicator were Luxembourg, Ireland, and Poland, which reduced the carbon intensity of transport energy consumption by $-1.9 \%, 1.9 \%$, and $-1.6 \%$ per year respectively across the period 2000-2012. The worst performing Member States were Slovenia, Malta, and Denmark, which increased the carbon intensity of transport energy consumption by $1.3 \%$, $1.0 \%$ and $0.4 \%$ per year over the period. The results suggest that a significant acceleration in the improvement of the carbon intensity of passenger transport is required to be in line with the future benchmark for deep decarbonisation.

Figure 6: historical improvement of carbon intensity of transport final energy consumption compared to future benchmarks from deep decarbonisation scenarios (\% change y-o-y)

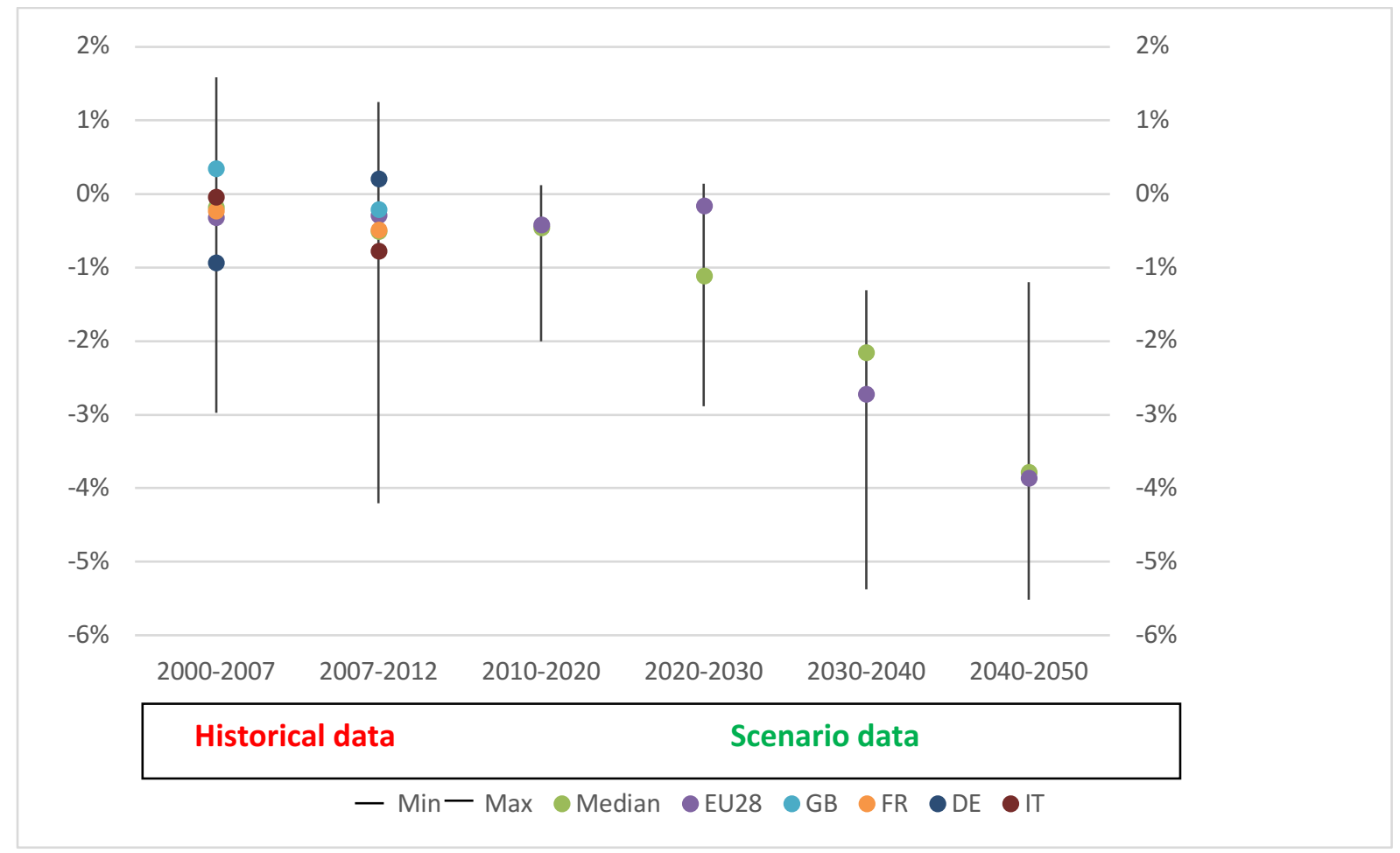

Source: authors based on (Criqui et al., 2015; Enerdata, 2016a; Hillebrandt et al., 2015; Paroussos et al., 2016; Pye et al., 2015; Virdis et al., 2015). N.B. for historical data, median, min and max refer to those values among all EU28 Member States. For future scenario data, median, min and max refer to these values from the scenario dataset compiled for UK, France, Germany, Italy, and the EU28. 


\subsection{Industry Sector Results}

\subsubsection{Defining the Future Benchmarks}

Due to the absence of industrial production data in the EU28 scenarios assessed in this study (Paroussos et al., 2016), the future benchmarks for the improvement of industrial energy intensity are derived solely from the 12 national level scenarios for France, Germany, Italy, the UK and Poland assessed in this study. Industrial energy intensity is defined in terms of industrial FEC per unit of industrial value added. In the scenario data assessed, the energy intensity of industrial production declines at a rate of $-1.42 \%$ per year and $-1.65 \%$ per year in the decades $2020-2030$ and $2030-2040$ respectively. The paper also analyses the carbon intensity of industrial FEC, defined as direct and indirect $\mathrm{CO}_{2}$ emissions/industrial FEC. In the scenario data assessed, the carbon intensity of industrial FEC declines by a rate of $-1.65 \%$ per year and $-3.73 \%$ per year in the decades $2020-2030$ and 2030 2040 respectively (median of the scenarios assessed).

The scenarios assessed in this project display a similar time profile for the decarbonisation of industrial final energy consumption, namely a significant "back-loading" of effort in later decades in the period 2010-2050. This is due to the reliance notably on technologies such as CCS and electrification of industrial processes in the decarbonisation strategies. It is interesting to note that the national scale scenarios assessed in this study tend to display a less extreme "back-loading" of effort in decarbonisation of industrial energy consumption. This explains the lower median of the scenarios assessed in the decades $2010-2020$ and 2020-2030, compared to the EU28 scenario assessed.

\subsubsection{Current Trends}

Between 2000 and 2014, the energy intensity of industrial production in the EU28 has fallen by -21\%, or a rate of $-1.6 \%$ per year. The $2007 / 8$ economic crisis appears to mark a structural break, with energy intensity falling by $-7 \%$ between 2000 and 2007, and -14\% between 2007 and 2014 in the EU28. Slovakia, Bulgaria, Romania, Cyprus, and the Czech Republic saw the strongest falls in industrial energy intensity, of $-61 \%,-54 \%,-53 \%,-51 \%$, and $-50 \%$ respectively between 2000 and 2014 in total. For most of these Member States, in contrast with the EU28 as a whole, the strongest reductions in industrial 
energy intensity occurred in the period 2000-2007 (the exceptions being Bulgaria and Romania, for which industrial energy intensity fell more strongly in the latter period). The Member States seeing the weakest performance improvements in this indicator were Hungary, Malta, Austria, Germany and Greece, for which industrial energy intensity changed by $-10 \%, 0 \%,+4 \%,+5 \%$, and $+7 \%$ respectively in total across the period. Figure 7 shows the change in industrial energy intensity historically for the EU28 and its Member States, and compares it with values for this indicator seen in the scenario literature assessed. The results suggest that the current progress seen on this indicator is broadly in line with the future benchmarks defined above.

Figure 7: historical improvement of energy intensity of industrial production to future benchmarks from deep decarbonisation scenarios (\% change y-o-y)

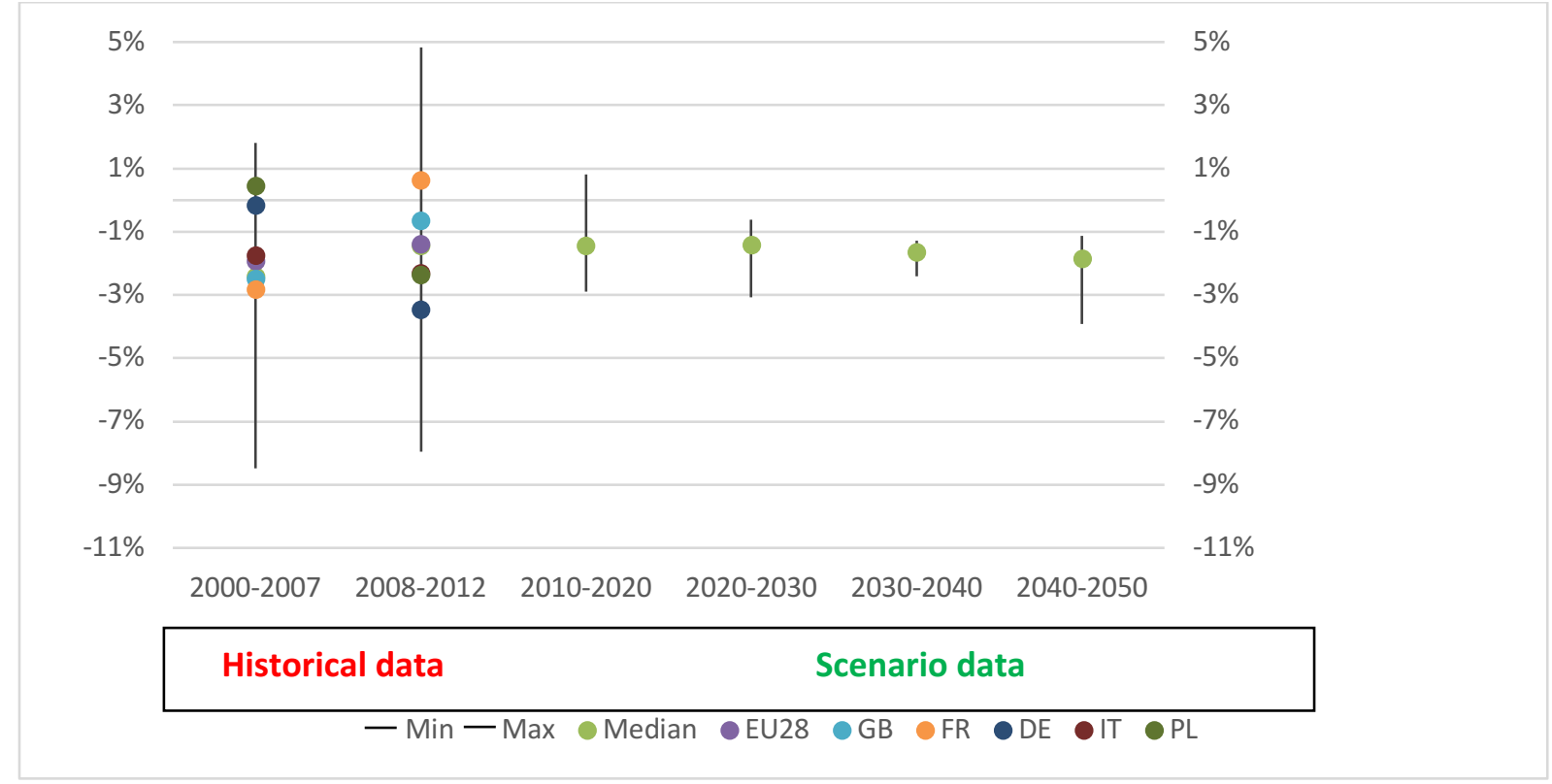

Source: authors based on (Criqui et al., 2015; Enerdata, 2016a; Hillebrandt et al., 2015; Paroussos et al., 2016; Pye et al., 2015; Virdis et al., 2015). N.B. for historical data, median, min and max refer to those values among all EU28 Member States. For future scenario data, median, min and max refer to these values from the scenario dataset compiled for UK, France, Germany, Italy and Poland. The EU28 is missing from the future scenario data due to the absence of industrial production data in the EU28 scenario. 
Figure 8 shows the historical evolution of carbon intensity of industrial final energy consumption for the EU28 and its Member States, and the evolution of this indicator in the deep decarbonisation scenarios assessed in this study. Between 2000 and 2013, the EU28 reduced the carbon intensity of industrial FEC by $-8 \%$, a rate of $-0.61 \%$ per year. The top performing Member States were Malta, Latvia, Romania, Sweden and Slovakia, which reduced the carbon intensity of industrial FEC by $-54 \%,-41 \%$, $28 \%,-27 \%$, and $-27 \%$ respectively over the period 2000 to 2013 in total. On the other hand, the United Kingdom, Luxembourg, Estonia, Greece, and the Netherlands experienced a change on this indicator of $+3 \%,+5 \%,+6 \%,+8 \%$, and $+28 \%$ respectively across the period 2000 to 2013 . In the decades 2020 2030 and $2030-2040$ the scenario median for this indicator is $-1.65 \%$ and $-3.73 \%$ per year respectively. This implies a significant acceleration of the decarbonisation of industrial energy consumption compared to observed historical trends. 
Figure 8: historical change of carbon intensity of industrial final energy consumption compared to future benchmarks from deep decarbonisations scenarios (\% change y-o-y)

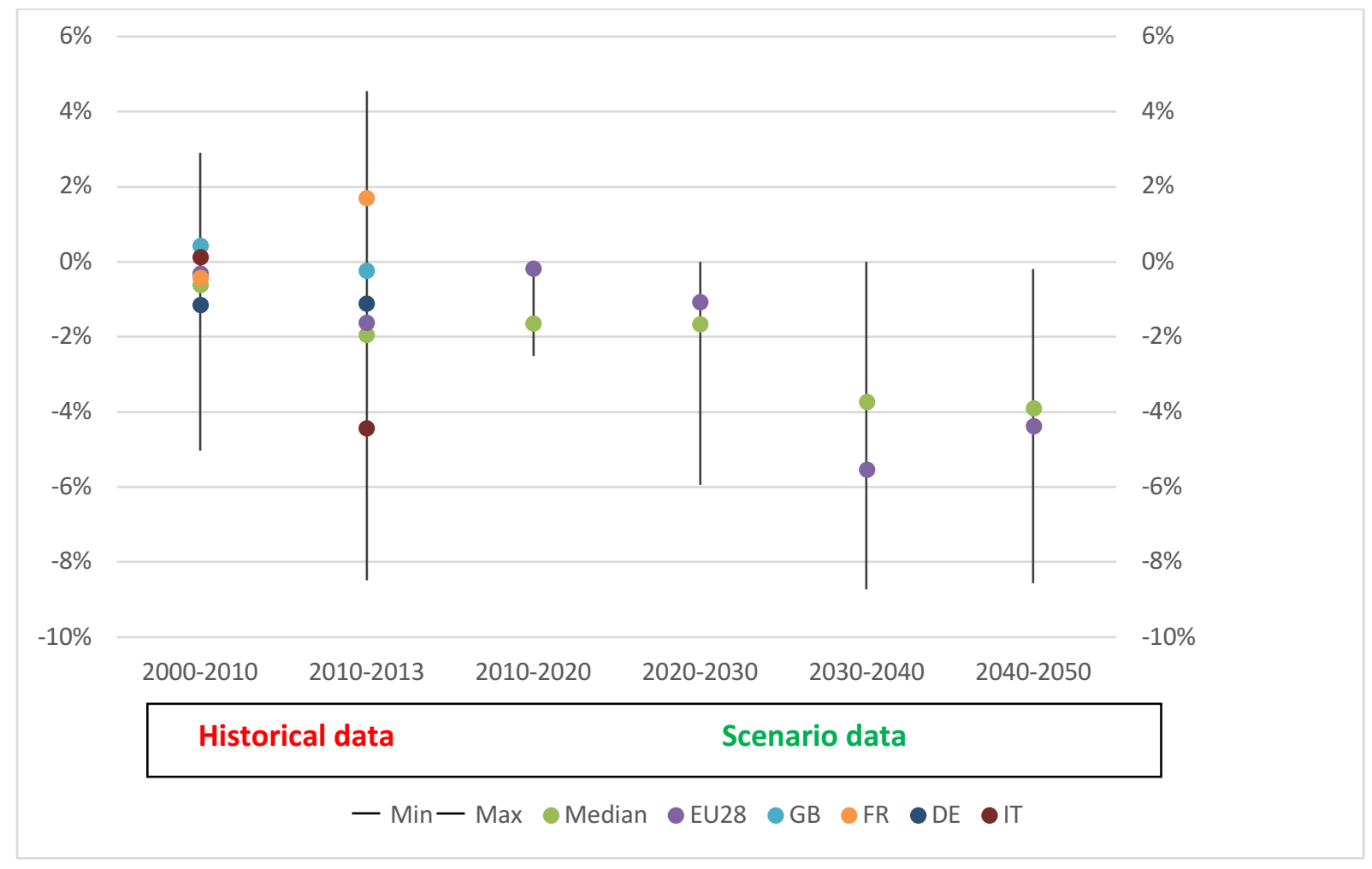

Source: authors based on (Criqui et al., 2015; Enerdata, 2016a; Hillebrandt et al., 2015; Paroussos et al., 2016; Pye et al., 2015; Virdis et al., 2015). N.B. for historical data, median, min and max refer to those values among all EU28 Member States. For future scenario data, median, min and max refer to these values from the scenario dataset compiled for UK, France, Germany, Italy, and the EU28.

\section{Conclusions and Discussion}

This paper has developed and applied a methodology for structuring and conducting an assessment of the decarbonisation of EU energy systems. The approach is based on the decomposition of decarbonisation into the drivers of the Kaya identity, and the comparison of historical trends with future benchmarks derived from the scenario literature. While the path towards decarbonisation is long and complex, the inertia of the socio-technical system of energy production and consumption is such that non-linearity is constrained by the turnover of the capital stock and cycles of investment, 
innovation, and deployment of decarbonisation options. Thus, a structured analysis of recent historical trends, in the light of future decarbonisation benchmarks, can provide useful insights into the adequacy of observed rates of change.

Several conclusions emerge from the analysis. Firstly, the methodology applied provides a useful and informative approach to tracking decarbonisation of energy systems. It requires, however, a significant availability of historical data and scenario data at a sufficient level of granularity to enable an analysis on the level of the Kaya identity components at sector level. This may limit its applicability outside of the EU context, for example for developing countries, where such detailed data is unavailable.

Secondly, the results show that significant progress has been made in the EU and its Member States in terms of the decarbonisation of energy systems. However, on a number of indicators assessed the results show that a substantial acceleration from historical levels is required in order to reach the rates of change seen on the future benchmarks. This holds particularly true for the electricity and transport sectors. In the case of industry, while its current performance is closer to the benchmarks, i) some of this is due to the structural effects of the $2007 / 8$ economic crisis; ii) the sector is still is facing a big challenge in terms of reducing its carbon intensity of energy with some key technologies for this making slow progress, such as CCS.

Particularly, the analysis suggests that future challenges will emerge in the decarbonisation of final energy consumption of energy in end-use sectors, where for all three end-use sectors the currently observed rates of change are below what is seen in the future benchmarks. The rate of decarbonisation of energy consumption in the residential sector would need to accelerate from $-0.6 \%$ per year in the historical data assessed, to $-2.9 \%$ per year in the decade $2020-2030$. In the transport sector, the rate of improvement of carbon intensity of energy would have to improve from $-0.31 \%$ per year, to $-1.1 \%$ per year in the decade 2020-2030. In the industry sector, the rate of improvement of the carbon intensity of energy would have to improve from $-0.61 \%$ per year in the historical data to $-1.65 \%$ per year in the decade 2020-2030. It should be noted that these historical rates mentioned are medians, 
and the historical data for some countries suggests that the future required rates of decarbonisation are possible (falling typically within the large range of historic changes observed in the different EU Member States). Table 1 provides an overview of the median results for each sector.

Table 1 : overview of results

\begin{tabular}{|c|c|c|c|}
\hline Sector & Indicator & $\begin{array}{l}\text { Historical trend } \\
\text { in rate of } \\
\text { change* }\end{array}$ & $\begin{array}{l}\text { Median value in rate of change } \\
\text { for } 2020-2030 \text { from the } \\
\text { scenarios assessed }\end{array}$ \\
\hline Electricity & $\begin{array}{l}\text { Carbon intensity of } \\
\text { electricity production }\end{array}$ & $-1.7 \%$ per year & $-5.6 \%$ per year \\
\hline \multirow[t]{2}{*}{$\begin{array}{l}\text { Residential } \\
\text { buildings }\end{array}$} & $\begin{array}{l}\text { Energy intensity of } \\
\text { residential buildings }\end{array}$ & $-1.8 \%$ per year & $-1.8 \%$ per year \\
\hline & $\begin{array}{l}\text { Carbon intensity of } \\
\text { residential final energy } \\
\text { consumption }\end{array}$ & $-0.6 \%$ per year & $-2.9 \%$ per year \\
\hline \multirow[t]{3}{*}{ Transport } & $\begin{array}{l}\text { Energy intensity of } \\
\text { passenger transport }\end{array}$ & $-0.54 \%$ per year & $-2.4 \%$ per year \\
\hline & $\begin{array}{l}\text { Energy intensity of freight } \\
\text { transport }\end{array}$ & $-0.7 \%$ per year & $-1.2 \%$ per year \\
\hline & $\begin{array}{l}\text { Carbon intensity of } \\
\text { transport final energy }\end{array}$ & $-0.31 \%$ per year & $-1.1 \%$ per year \\
\hline \multirow[t]{2}{*}{ Industry } & $\begin{array}{l}\text { Energy intensity of } \\
\text { industrial production }\end{array}$ & $-1.6 \%$ per year & $-1.4 \%$ per year \\
\hline & $\begin{array}{l}\text { Carbon intensity of } \\
\text { industrial final energy }\end{array}$ & $-0.61 \%$ per year & $-1.6 \%$ per year \\
\hline
\end{tabular}

Source: authors. ${ }^{*}$ the historical period assessed here is different for different indicators due to data availability. 
In terms of a research agenda going forward, this paper has applied the methodology developed for power generation and energy end use sectors, taking energy intensity and carbon intensity as the main indicators assessed. Future research could look in more detail at the drivers of the observed changes on these indicators, in terms of the level and composition of activity in each sector and the deployment of low-carbon, energy efficient technologies. More broadly, the methodology applied in the paper provides an example of how the research community and international organisations could complement the transparency mechanism developed by the Paris Agreement on climate change, in order to improve the understanding of progress toward and the requirements of the shift to lowcarbon energy systems. The application of this methodology outside the EU would provide a useful complement to efforts, for example under the UNFCCC or IEA, to understand the scope and rate of the energy transition currently emerging, for example in the electricity sector.

\section{References}

Bataille, C., Waisman, H., Colombier, M., Segafredo, L., Williams, J., 2016a. The Deep Decarbonization Pathways Project (DDPP): insights and emerging issues. Clim. Policy 16, S1-S6. doi:10.1080/14693062.2016.1179620

Bataille, C., Waisman, H., Colombier, M., Segafredo, L., Williams, J., Jotzo, F., 2016b. The need for national deep decarbonization pathways for effective climate policy. Clim. Policy 16, S7-S26. doi:10.1080/14693062.2016.1173005

Blanco, G., Gerlagh, R., Suh, S., Barrett, J., Coninck, H.C. de, Morejon, C.F.D., Mathur, R., Nakicenovic, N., Ahenkora, A.O., Pan, J., Pathak, H., Rice, J., Richels, R., Smith, S.J., Stern, D.I., Toth, F.L., Zhou, P., 2014. Drivers, Trends and Mitigation, in: 2Climate Change 2014: Mitigation of Climate Change. Contribution of Working Group III to the Fifth Assessment Report of the 
Intergovernmental Panel on Climate Change. Cambridge University Press, Cambridge, UK, and New York, USA, pp. 351-412.

BMUB, 2016. Klimaschutzplan 2050. Berlin.

Bruckner, T., Bashmakov, I.A., Mulugetta, Y., Chum, H., Navarro, A. de la V., Edmonds, J., Faaij, A., Fungtammasan, B., Garg, A., Hertwich, E., Honnery, D., Infield, D., Kainuma, M., Khennas, S., Kim, S., Nimir, H.B., Riahi, K., Strachan, N., Wiser, R., Zhang, X., 2014. Energy Systems, in: Climate Change 2014: Mitigation of Climate Change. Contribution of Working Group III to the Fifth Assessment Report of the Intergovernmental Panel on Climate Change. Cambridge University Press, Cambridge, UK, and New York, USA, pp. 511-598.

Bukowski, M. (ed. ., 2013. 2050.pl The Journey to a Low Emissions Future. Warsaw.

Capros, P., Paroussos, L., Fragkos, P., Tsani, S., Boitier, B., Wagner, F., Busch, S., Resch, G., Blesl, M., Bollen, J., 2014a. Description of models and scenarios used to assess European decarbonisation pathways. Energy Strateg. Rev. 2, 220-230. doi:http://dx.doi.org/10.1016/j.esr.2013.12.008

Capros, P., Paroussos, L., Fragkos, P., Tsani, S., Boitier, B., Wagner, F., Busch, S., Resch, G., Blesl, M., Bollen, J., 2014b. European decarbonisation pathways under alternative technological and policy choices : A multi-model analysis. Energy Strateg. Rev. 2, 231-245. doi:10.1016/j.esr.2013.12.007

Cefic, 2013. European chemistry for growth: Unlocking a competitive, low carbon and energy efficient future.

Clarke, L.E., Jiang, K., Akimoto, K., Babiker, M., Blanford, G., Fisher-Vanden, K., Hourcade, J.-C., Krey, 
V., Kriegler, E., Löschel, A., McCollum, D., Paltsev, S., Rose, S., Shukla, P.R., Tavoni, M., van der Zwaan, B.C.C., van Vuuren, D.P., 2014. Assessing Transformation Pathways, in: Climate Change 2014: Mitigation of Climate Change. Contribution of Working Group III to the Fifth Assessment Report of the Intergovernmental Panel on Climate Change. Cambridge University Press, Cambridge, UK, and New York, USA, pp. 413-510.

Committee on Climate Change, 2016. Meeting Carbon Budgets - 2016 Progress Report to Parliament. London.

Criqui, P., Mathy, S., Hourcade, J.-C., 2015. Pathways to Deep Decarbonization in France, DDPP Project Report. Paris.

Enerdata, 2017. Global Energy and CO2 Data [WWW Document]. URL http://globaldata.enerdata.net/home/ (accessed 12.6.16).

Enerdata, 2016. ODYSSEE database on energy efficiency data \& indicators [WWW Document]. URL http://odyssee.enerdata.net/home/ (accessed 12.6.16).

European Climate Foundation, 2013. From Roadmaps to Reality: A framework for power sector decarbonisation in Europe. Brussels.

European Commission, 2016b. Clean Energy For All Europeans. Brussels.

European Commission, 2016a. EU Reference Scenario 2016: Energy, transport and GHG emissions Trends to 2050. Brussels.

European Commission, 2015. Monitoring progress towards the Energy Union objectives - Concept 
and first analysis of key indicators Accompanying the document COMMUNICATION FROM THE COMMISSION TO THE EUROPEAN PARLIAMENT, THE COUNCIL, THE EUROPEAN ECONOMIC AND SOCIAL COMMITTEE, THE COM (No. 2015/0243 final), SWD. Brussels.

European Commission, 2011a. Roadmap to a competitive low-carbon economy in 2050. Brussels.

European Commission, 2011b. Energy Roadmap 2050 COM(2011) 885 final. Brussels.

European Council, 2009. Presidency Conclusions [WWW Document]. URL

https://www.consilium.europa.eu/uedocs/cms_data/docs/pressdata/en/ec/110889.pdf (accessed 12.6.16).

European Environment Agency, 2015. Trends and projections in Europe 2015 - Tracking progress towards Europe's climate and energy targets. Copenhagen.

European Parliament and Council, 2013. Regulation (EU) No 525/2013 of the European Parliament and of the Council of 21 May 2013 on a mechanism for monitoring and reporting greenhouse gas emissions and for reporting other information at national and Union level relevant to climate change and re. Brussels: Official Journal of the European Union, European Union.

European Union, 2015. Intended Nationally Determined Contribution of the EU and its Member States 1-7. doi:10.1613/jair.301

Foerster, H., Schumacher, K., De Cian, E., Huebler, M., Keppo, I., Mima, S., Sands, R., 2013. European Energy Efficiency and Decarbonization Strategies Beyond 2050: A Sectoral Multi-Model Decomposition. Clim. Chang. Econ. 4. doi:10.1142/S2010007813400046 
Hillebrandt, K., Samadi, S., Fischedick, M., Eckstein, S., Höller, S., Janßen, T., Kamps, K., Krüger, C., Lechtenböhmer, S., Nigge, J., Pastowski, A., Sellke, P., 2015. Pathways to Deep Decarbonization in Germany, DDPP Project Report. Paris.

HMG, 2011. The Carbon Plan 2050. London, United Kingdom.

IEA, 2017. Tracking Clean Energy Progress 2017: Energy Technology Perspectives 2017 Excerpt. Paris.

IEA, 2016. Energy, Climate Change and Environment: 2016 Insights. Paris.

IEA, IRENA, 2017. Perspectives for the Energy Transition: Investment Needs for a Low-Carbon Energy System. Berlin.

Kebmin, 2011. Energy Strategy 2050. Copenhagen.

Knopf, B., Bakken, B., Carrara, S., Kanudia, A., Keppo, I., Koljonen, T., Mima, S., Schmid, E., van Vuuren, D.P., 2013. Transforming the European Energy System: Member States' Prospects within the EU Framework. Clim. Chang. Econ. 4, 1-26. doi:10.1142/S2010007813400058

Mathy, S., Criqui, P., Knoop, K., Fischedick, M., Samadi, S., 2016. Uncertainty management and the dynamic adjustment of deep decarbonization pathways. Clim. Policy 16, S47-S62. doi:10.1080/14693062.2016.1179618

MEDDEM, 2015. Stratégie Nationale Bas Carbone. Paris.

Metz, B., Davidson, O.R., Bosch, P.R., Dave, R., Meyer, L.A. (Eds.), 2007. Contribution of Working Group III to the Fourth Assessment Report of the Intergovernmental Panel on Climate Change, 
2007. Cambridge University Press, Cambridge, UK, and New York, USA.

Ministry of EL\&l, 2011. Energierapport 2011. The Hague.

Ministry of lenM, 2011. Klimaatbrief 2050. Uitdagingen voor Nederland bij het streven naar een concurrerend, klimaatneutraal Europa. The Hague.

MiSE, 2013. Italy's National Energy Strategy: For a more competitive and sustainable energy. Rome.

Naturvardsverket, 2012. Underlag till en färdplan för ett Sverige utan klimatutsläpp 2050. Stockholm.

Neuhoff, K., Acworth, W., Ancygier, A., Branger, F., Christmas, I., Haussner, M., Ismer, R., van Rooij, A., Sartor, O., Sato, M., Schopp, A., 2014a. Carbon Control and Competitiveness Post 2020: The Steel Report. London.

Neuhoff, K., Acworth, W., Ancygier, A., Branger, F., Christmas, I., Haussner, M., Ismer, R., van Rooij, A., Sartor, O., Sato, M., Schopp, A., 2014b. Carbon Control and Competitiveness Post 2020: The Cement Report. London.

Paroussos, L., Fragkos, P., Capros, P., 2016. A model-based analysis of the European Intended Nationally Determined Contribution (No. N07/16), Studies. Paris.

Portuguese Environment Agency, 2012. Roteiro Nacional de Baixo Carbono 2050. Lisbon.

Pye, S., Anandarajah, G., Fais, B., McGlade, C., Strachan, N., 2015. Pathways to Deep Decarbonisation in the United Kingdom, DDPP Project Report. Paris. 
Spencer, T., Piefederici, R., Waisman, H., Colombier, M., Bertram, C., Kriegler, E., Luderer, G., Humpenöder, F., Popp, A., Edenhofer, O., Elzen, M. Den, Vuuren, D. van, Soest, H. van, Paroussos, L., Fragkos, P., Kainuma, M., Masui, T., Oshiro, K., Akimoto, K., Tehrani, B.S., Sano, F., Oda, J., Clarke, L., Iyer, G., Edmonds, J., Fei, T., Sha, F., Kejun, J., Köberle, A.C., Szklo, A., Lucena, A.F.P., Portugal-Pereira, J., Rochedo, P., Schaeffer, R., Awasthy, A., Shrivastava, M.K., Mathur, R., Rogelj, J., Jewell, J., Riahi, K., Garg, A., 2015. Beyond the numbers: Understanding the transformation induced by INDCs (No. N05/15), IDDRI, Study. Paris.

TEM, 2014. Energy and Climate Roadmap 2050. Helsinki.

Virdis, M.R., Gaeta, M., Cian, E. De, Parrado, R., Martini, C., Tommasino, M.C., Verdolini, E., Alloisio, I., 2015. Pathways to Deep Decarbonization in Italy 2015, DDPP Project Report. Paris. 